MAURICIO VICO

DIRECTOR DEPARTAMENTO DE DISEÑO

FACULTAD DE ARQUITECTURA Y URBANISMO

UNIVERSIDAD DE CHILE

MVICO@UCHILEFAU.CL

\section{Historia de los pueblos a través del afiche o cartel}

History of peoples through the poster

El cartel, más particularmente, carece de esa presencia misteriosa que rodea al cuadro, y en su expresión tan humilde y poco pretenciosa no necesita "posar" para ser obra de arte. Función social del cartel, Josep Renau.

El objeto de los artículos que aquí se presentan ha sido la localización, rescate, datación, catalogación y documentación del conjunto de carteles o afiches o poster que se han producido en países como México, Portugal, Chile, Rusia y Portugal durante un período que abarca varios siglos o varias décadas de los últimos cien años.

El conjunto de carteles estudiados incluye los que se confeccionaron en el ámbito de la propaganda política y otros en la esfera de lo cultural y social. Dar con los carteles y rescatarlos del olvido ha llevado a los investigadores a una ingente labor de búsqueda de estos impresos y de cuanto material gráfico o periodístico pudiera servir para identificar, datar y documentar los ejemplares localizados. Varios de ellos han participado resumiendo sus trabajos anteriores o construyendo nuevos artículos a partir de sus tesis de doctorado o magíster, y otros levantando nuevas miradas críticas.

Cabe preguntarse por qué tuvieron que pasar tantos años para que se hiciera público un material visual tan relevante y que construyó una iconografía que en muchos lugares ha sido espacio de significación histórica y trayectoria política, entendiendo que el afiche o cartel viene actuando ya por varios siglos. Las respuestas pueden estar en la sociología, la antropología social, el arte, la estética, hasta la historia de la tecnología. Acaso la gente y en especial la intelectualidad ha mirado esta pieza como un objeto secundario, incluso con cierto desdén, restándose de aportar datos para una historiografía más completa. Sin embargo, las nuevas miradas de la historia comienzan a reconocer en la iconografía y la iconología un gran aporte de este género que proporciona datos, muestra transformaciones estilísticas, sociales, tecnológicas y políticas de una sociedad.

Una de las mayores aportaciones de estas investigaciones ha sido haber creado una colección de carteles que se pueda consultar, mostrar, exponer y divulgar dentro y fuera de los propios países donde se revisaron, facilitando una nueva interpretación de la historia del cartel mundial que encontramos en tesis y libros publicados por varios de estos investigadores.

La existencia de estos afiches y la presencia de esta producción han puesto de relieve su importancia histórica, despertándose el interés por saber más de ellos, leer su relato y su devenir; información recabada a través de entrevistas, archivos, revisión de documentos, fichas de catalogación de cada obra y otros. En ese sentido, su mensaje es intemporal y la campaña que llevaron a cabo en su momento sigue vigente en años posteriores, por lo que pueden volverse a reiterar sus temas, muchas veces construyéndose a modo de hipertexto. Es lo que ocurre con tantas campañas de sensibilización social, de propaganda política o también en el campo de la difusión cultural. De ahí la necesidad de buscar otras muchas fuentes de información para fecharlos 
en un sentido sincrónico, así como para disponer de la información necesaria para documentarlos y catalogarlos como obras importantes en la historia del diseño gráfico local e internacional.

Que esto último ocurriera no debería sorprender a nadie: por la alta calidad gráfica de la mayoría de estas piezas; además, por su gran interés como objeto material e inmaterial de la cultura, tanto en el contexto de la historia política y social de estos países, como también para la historia del diseño gráfico. Se verá en los artículos siguientes elementos gráficos constantes en las obras, como son el uso de fuentes tipográficas, tanto de tipos en plomo, letras rotuladas, hasta digitales, el uso variado de técnicas de las más clásicas hasta las actuales. Además, la profundidad y claridad conceptual del mensaje, su lenguaje visual, las propuestas estéticas desde la misma concepción del afiche como espejo de la sociedad. Y cuán a menudo han fluido estilos internacionales que han dominado la escena a través de los siglos y otras veces durante períodos muy cortos. De ahí su relevancia y que merece ponerse en valor a través de esta publicación del número 3 de RChD: creación y pensamiento. El factor que les confiere unidad es el tema tratado. La mayor parte de este material tiene como eje la propaganda política, social y cultural. Además, es un trabajo de estudio pendiente por los alcances de distribución masiva y permanente del afiche, $y$ también sus propuestas discursivas y experimentales.

Así, el escrito por Nicole Cristi y Javiera Manzi Construcción de una trinchera gráfica: la experiencia de la Agrupación de Plásticos Jóvenes (APJ) y el Tallersol durante la dictadura en Chile resume el aporte de estas agrupaciones y su rol político en tiempos de la dictadura en Chile (1973-1989) a través del cartelismo como soporte de promoción y agitación desde el período de la Unidad Popular, como una utopía gráfica y tras el golpe militar se asume en una práctica de resistencia. El artículo incursiona en la relación entre gráfica y política durante la década de los setenta y ochenta a partir de dos colectivos: la Agrupación de Plásticos Jóvenes (APJ) y el Centro Cultural Tallersol. El artículo Una historia de diseño del cartel en Portugal del siglo XVII al XIX de la académica de la Universidad de Aveiro, Portugal, Dra. Helena Barbosa, es la revisión de la historia del cartel durante tres siglos en ese país. Busca comprender cómo ha cambiado este soporte durante el tiempo. Este artículo muestra una serie de aspectos históricos como también aspectos de su reproducción. La autora propone la división en tres secciones, dedicadas a cada siglo tratado.

El artículo del Dr. Jacques Le Bourgeois El cartel político soviético, una especificidad, es un extracto de su tesis de doctorado en Historia, donde propone un acercamiento al afiche de propaganda soviética desde la Revolución de Octubre hasta la Perestroika. Son productos característicos de la cultura rusa, como indica el autor, y también inspirados en las tradiciones pictóricas rusas Ilamadas "lubok". Con un lenguaje artístico proveniente de la Academia de Bellas Artes utiliza, sin embargo, un mensaje explícito que tiene como esencia la ideología socialista. Y como indica Le Bourgeois, "la originalidad está justamente en lo que el autor califica de 'consubstancialidad', usando una palabra del campo religioso para definir esta mezcla inalterable artística y política que caracteriza al cartel soviético".

Otro de los trabajos es el artículo El cartel político en México: memoria, reflexiones e inflexiones, del investigador mexicano Dr. José Manuel Morelos. El autor busca establecer en esta deriva de su tesis doctoral un reconocimiento del cartel y su complejidad interpretativa, su multiplicidad de valores 
y la necesidad de establecer iniciativas de preservación de los carteles de contenido político en México, con el objetivo de proteger una memoria, un patrimonio social e ideológico para la reconstrucción de la identidad.

Finalmente, el artículo del profesor e investigador de la Escuela de Diseño de la Universidad Católica Dr. Pedro Álvarez Caselli, que denomina Post cartel en Chile: la pérdida del aura y su devaluación en tiempos de Google analiza el cartel desde una perspectiva cualitativa, considerando la circulación de carteles tanto en formato impreso y digital, y el desplazamiento del cartel y su circulación en las redes sociales y asociados al ámbito del espectáculo, el entretenimiento y la cultura en el contexto local actual, y lo hace a través de una discusión bibliográfica. El objetivo, como lo plantea el autor "documentar, analizar y abrir un debate respecto al actual estatuto de la producción de carteles en un escenario donde nuestra subjetividad se ha ampliado en razón de un profundo cambio en los modos de producción y circulación de esta herramienta de comunicación, cuestionando la autonomía del diseñador". En efecto, como expone Álvarez, el cartel hoy se vuelve cada día más complejo debido a su circulación, tanto en el territorio urbano como en las redes sociales. 